\title{
THE STUDY OF RELATIONSHIP BETWEEN SOCIAL INTELLIGENCE AND ORGANIZATIONAL PERFORMANCE (CASE STUDY: ARDABIL REGIONAL WATER COMPANY'S MANAGERS)
}

\author{
Habib Ebrahimpoor ${ }^{\mathrm{a} 1}$, Adel Zahed ${ }^{\mathrm{b} 2}$, Azim Elyasi $^{\mathrm{c} 3}$ \\ a. Assistant Professor of University of Mohaghegh Ardabili \\ b. Associate Professor of University of Mohaghegh Ardabili \\ c. Department of MBA Science and Research Branch, Islamic Azad University, Ardabil
}

\begin{abstract}
Aim:The aim of this study was to investigate the relationships among dimensions of social intelligence, social skills, social information processing, social awareness, social desirability of organizational performance. Methods: This research was a descriptive study. The population in this study comprised all experts, assistants and managers of regional water companies in Ardabil province, and was about 164 randomly selected people. And to gather data from field methods the means of questionnaires were used. Tromso questionnaire was chosen and designed to measure social intelligence and organizational performance by assessing specific questions about Balanced Scorecard as independent variable. To achieve the multiplier effect of each variable on the dependent variable, Pearson correlation test was performed. Results indicated that social skills, social information processing, social awareness and social desirability of improving organizational performance had the most important part in social information processing, and social awareness and social skills played a secondary role in improving performance.
\end{abstract}

Key words: organizational performance, social intelligence, social skills, social information processing, social consciousness, social desirability.

\footnotetext{
1. ebrahimpourh@yahoo.com

2.adelzahed@yahoo.com

3.az_elyasi@yahoo.com
} 


\section{Introduction}

Social intelligence as one of the new areas in psychology, in the recent decades, owing to its appealing and widespread aspects has attracted the attention of psychologists, and psychiatrists, as well as other experts in various fields such as organization and management.

Social intelligence is an inclusive term that embraces a wide range of skills and personal characteristics and usually refers to those interpersonal and intrapersonal skills that transcend specific areas of the previous knowledge such as intelligence and technical or professional skills (Rezayee, and Khalilzadeh, 2009:25). Today a lot of researchers intend to obtain deep insight about the factors effective in maximal use of the staff and managers' capabilities. A review of literature on the issue shows that the focus of diverse studies has been on the cognitive aspect of performance and the effect of emotional aspects has been generally neglected in the studies conducted on organizational behavior (Brown, 2005:25). For long, intelligence quota has been regarded as the main index of success in life. According to outcomes of studies done, the percentage of IQ role in an ideal performance has not been reported more than $10 \%$ and even sometimes it has been about $4 \%$ (Sobhani nejad and Yuzbashi, 2006: 27). When the point stands out that one wants to move up the hierarchy. And it is in the higher levels that the essentiality of social intelligence compared to IQ rises. In this regard, Goleman and his colleagues hold that social intelligence is of considerable use in all the organizational classes, but it takes on vital importance when it comes to the managerial hierarchy (Babayee, and Mo'meni, 2005: 35).

Social intelligence has been defined as the ability to establish relationship with others, intrapersonal knowledge, ability to judge about others' feelings, temperaments and incentives, effective social performance/function, ability to sympathize, and being skilled in decoding nonverbalsigns. Thus, the researchers have concluded that intelligence embraces abilities beyond general intelligence (Shot et al, 1998: 169). And they consider social intelligence as a new way of thinking about social media (Schawl, 2010: 6). One of the main factors in advancement of a live and dynamic organization is its human force. Because human force is considered as the main source of every organization, the organizations should program to make optimal use of it. As a matter of fact, today those organizations are successful and can achieve their goals that have strong and committed human force, accentuate customer-orientedness and profitability rise, and regularly improve their systems and processes (Hsien, 2008:525). Making optimal use of available human force is related to having aware, qualified and adroit/ skilled manager. The complicatedness of society process, increase of competition, advancement of science and technology and consequently the increase of demands and the development of organizations require that efficient and skilled manager to be employed to manage organizations' affairs. This point which is related to the issue of human force can provide background for improving profitability through removing barriers, meeting necessary requirements, gathering efficient human force, and the required material resources. After adequately combining and coordinating them, they achieve those goals via making optimal use of them.

There are many factors that affect the performance of managers or are associated with it. It can be said that in the organizations that have impacting nature and need to offer new services to customers, variables like managers' ability in establishing relationship with personnel and customers, as well as their ability in recognition of the personal and social characteristics of the individuals and generally their high social intelligence (social skills, social information processing, social awareness and social desirability) which entails the managers' ability in decision making at times of crisis, is taken as a competitive advantage for the organization. The studies have explored a positive and significant relationship between managers' social intelligence and the teachers' satisfaction with their job. Among three components of social intelligence the component of social skills, and processing 
social information are the best predictors of job satisfaction (Rezayee \& Khalilzadeh, 2009:122). In a study that emotional intelligence has been taken equal to social intelligence, a significant relationship has been explored between self-awareness, self-management, social awareness, and ability to organize relationships among the faculty members, and their training/educational performance. Furthermore, the studies have revealed that workspace as a an intervening variable modifies the relationship between self-awareness and self-management and affects the relationship between social awareness and their capability for handling educational relations (Noorayee, \& Saee Arasi, 2010: 74). Regarding the effect of social intelligence on performance of companies and organizations, the present article intends to examine the relationship between them and address the following questions: What is social intelligence? What are the similarities and differences between social intelligence and emotional intelligence? What are the indicators that point to organizational performance? What is the effect of social intelligence on the organizational performance of companies?

\section{Social intelligence}

In the western societies, the analytical concept of intelligence in the literature of management is more cognitive and includes processing information. Whereas the integrative eastern approach to intelligence involves different components of human's experience and performance, such as cognition, intuition, and emotion in an (integrated) relationship (Nuzzle, 2004: 42). Intelligence has been considered as a level of skills and cognition which is readily accessible for solving problem (Samadi, 2006:104). Intelligence is a set of cognitive abilities that provide possibility of knowledge acquisition and learning, and solving problems (Aghayar, \& Sharifi-Daramadi, 2007: 36)

Different types of Intelligence has been mentioned in typology of intelligence, including natural intelligence, spiritual intelligence, cognitive intelligence, artificial intelligence, physical intelligence, cultural intelligence, organizational intelligence, emotional intelligence, business intelligence, moral intelligence, competitive intelligence, and multiple intelligences. Social intelligence and emotional intelligence are often used interchangeably and taken synonymous with each other mistakenly. Social intelligence, despite its similarities with other intelligences is more specific than emotional intelligence and has unique specifications and characteristics.

Social intelligence can be defined as the ability to control emotions and feelings; therefore it can aid mental activities, decision making and communication. Based on the findings of Goleman, those who have high social intelligence know how to control and channel their own and others' emotions and feelings (Goalman, 1998: 94). Social intelligence is one of the first choices in completing the traditional concepts of capability (Beheshtifar, \& Roasayee, 2012:201). Social intelligence indicates that to what extent managers possess capabilities like social skills, social information processing, social awareness, and social desirability. Hereupon, social intelligence contains four components: social skills, social information processing, social awareness, and social desirability.

- Social skills are key factors in recognition of points of strength and weakness. All the units that have this ability including managers, leaders, and experts are continuously looking for receiving feedback on their performance and learn from their failures.

- Processing social information reflects a person's ability in regulating distressing emotions like anxiety or nervousness and managing such situations.

- Social awareness; an individual through becoming aware of others' feelings, tastes, and needs identifies the paradoxical situations, and makes use of this source of information to establish a good relationship with them. Goleman believes that understanding others' feeling while 
making decision and ethical judgments is of high value and lack of sympathy is a fundamental shortcoming in social intelligence (Aristu, 2008: 67).

- Social desirability; this component denotes how to interact with individuals in the emotional situations which is also referred as social skill. Goleman holds that the individuals who intend to build relationships with others effectively need to have the ability to distinguish, separate, and control their feelings. Only through having superior social skills, the individuals know where and when to show emotional state (Nwkah and Ahizu, 2009: 867)

\section{Social Intelligence and Emotional Intelligence}

A review of theoretical principles and the research studies' findings and the definitions available in the Persian literature indicates that, social and emotional intelligence, while distinct from each other, have been considered synonymous in all of them. Accordingly, despite the components of social intelligence are applied in emotional intelligence, social intelligence goes beyond it. The emphasis of social intelligence is on the individual and internal control and management of excitements while emotional intelligence puts stress on the control and management of feeling in relation to others. Moreover, it focuses on effective management of interactions between people. Although through cursory look over definitions of social and emotional intelligence, no particular point of difference can be detected, what draws line between them is the existence of various components in the features of social and emotional intelligence. Social intelligence examines the ability to use communication skills, friendly relationships with others, social behavior and empathy with others (Mohammadian Hossein Abadi, 2006: 16), whereas emotional intelligence is a collection of individual talents and skills in understanding how to express or control emotions and feelings, a person with high emotional intelligence is skilled in the areas of identification, understanding and control of emotions (Nouraei, and Saee Arasi, 2010: 159). The framework of social skills in Goleman model comprises two major groups, namely: 1) personal competencies which in turn include self-awareness and self-management, and 2) social qualifications that embrace social awareness and organizing relations. In addition to the specified framework for social intelligence, in the present study the researchers have tried to take advantage of other components in the field of social intelligence. Thence, in the present article adopting the Tromso (2010) and Gini's (2005) perspective to social intelligence, the components of social acceptance and social desirability were added to social intelligence. However, it is worth mentioning that these two components were not considered in emotional intelligence. Thus, a divergent view to social intelligence and emotional intelligence was put forward.

\section{Organizational performance}

Performance literally means the state or quality of a function, and organizational performance is a general construct that refers to quality of organizational operations/functions (Nili et al, 2002: 2). Thorough and critical evaluation is essential for any organization (Hajiani et al, 1389: 77). Organizational performance is an index that measures the degree to which an organization or institute has achieved its goals (Ho, 2008:112). By another definition, organizational performance is a tool for achieving better outcomes of organization, teams and individuals via considering certain standards and objectives. It is obvious that whenever individuals are aware of what they are expected to do, and are involved in setting those expectations, they make great effort to fulfill them as well (Armstrong, 2006: 242). There are two main trends in evaluation of performance: 1) economic perspective that emphasizes the importance of external factors of market such as, competitive position, and 2) organizational perspective which is based on the behavioral and sociological theories: ديدمان, and their compatibility with the environment (Rahnavard, 2008: 82). In addition, several indicators have been 
presented to measure performance. One of the models in this field is BSC model with four aspects (or perspectives) of finance, customer, internal processes and learning and growth. The objectives of using balanced score card are: 1. creating a framework for describing organizations' strategy by considering the financial, customer, internal process, and learning and growth aspects, 2. Establishing a system that can bridge the gap between the objectives stated by senior managers and those perceived by staff, and 3. Setting a system for evaluating past performance and directing future performance (Atafar et al, 2010: 99). Due to comprehensiveness of BSC indicators in evaluating performance and its increasing functionality, the four indicators of this model have been employed in the present research study for evaluating and measuring the performance. Social intelligence like other components discussed in the area of management influences organizational performance. This paper seeks to examine the relationship between these two variables and tries to achieve the amount of organizational performance through clarifying the components of social intelligence.

\section{The conceptual model of research}

In order to achieve the conceptual model, the approach of Tromso (2010) and Gianluca Gini (2005) to social intelligence, and the performance indicators of Balanced Scorecard model (Kaplan and Norton, 2005) have been taken in this study, i.e., it is the combination of these two conceptual models that underlies the current study.

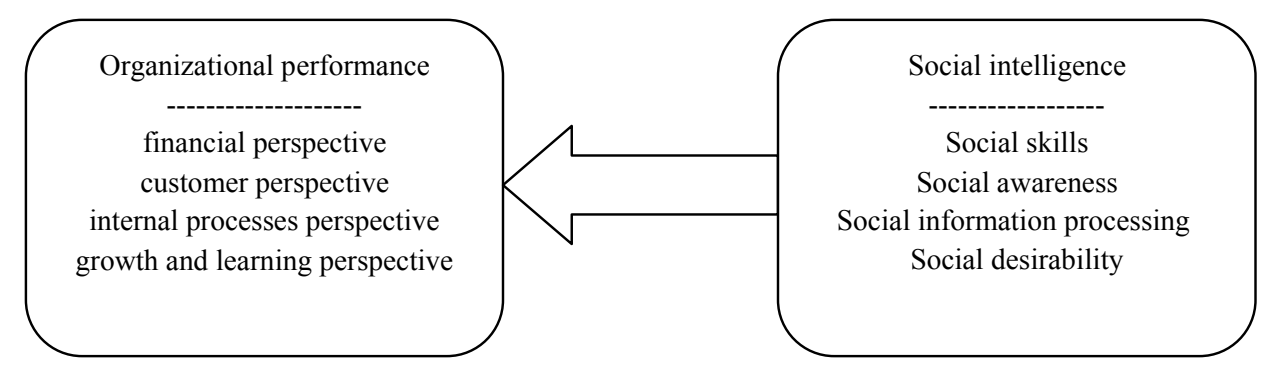

Figure1. The Conceptual model of research, social intelligence and organizational performance

\section{Research hypotheses}

The main hypothesis: Is there any significant relationship between social intelligence and organizational performance?

Secondary/ sub- hypotheses

1. Is there any significant relationship between social skills and organizational performance?

2. Is there any significant relationship between social information processing and organizational performance?

3. Is there any significant relationship between social awareness and organizational performance?

4. Is there any significant relationship between social desirability and organizational performance?

5. To what extent can each component of social intelligence, as a predictive variable, predict the dispersion of criterion variable (organizational performance)?

\section{Methodology}


The present study was descriptive and was conducted with applied purpose. The theoretical principles that underpin the present study were chosen out through library and internet research methods. The population consisted of 300 managers and experts from Ardabil regional water company. The number of sample under study was estimated 164, using Cochran sampling techniques. Simple random sampling was used for drawing sample from population. To test the research hypotheses and analyze the data for determining the degree of clarification of dependent variables through independent variables, Pearson correlation test and multivariate regression were performed. Questionnaires were employed to gather data. Cronbach's alpha coefficient was used to determine the validity of the questionnaire, the coefficient for the social intelligence's variables was 0.75 and for the organizational performance variables was 0.79 that indicated good reliability of the questionnaire.

\section{Research Findings}

The results obtained from the analysis of descriptive statistics in the age range of respondents indicated that $9.8 \%$ of 164 respondents were below 30 years of age, $46.3 \%$ were between 30 and 39, $33.5 \%$ were between 40 and, $10.4 \%$ were between 50 and 59 years of age. Moreover, $90.2 \%$ of respondents were male and $9.8 \%$ were female, $92.1 \%$ were married, and $7.9 \%$ were single. The results related to education of respondents showed 3\% for those with diploma, $9.8 \%$ for the respondents with associate degree, $78 \%$ for those with bachelor's degree, and $9.2 \%$ for participants with master's degree or higher. The results obtained on their vocational background revealed 1 to 10 years for $46.3 \%$ of them, 11 to 20 years for 37.2 percent and 21 to 30 years of experience for $16.5 \%$ of the respondents.

Descriptive statistics for social intelligence had four components in Table 1. In this table, the mean, standard deviation is specified separately for each component. Of the indicators measuring the size of the independent variable, acceptance of social information had the highest average and social awareness had the lowest average. The standard deviation of the component with the highest average was 3.65 and the component with the lowest average was 2.53. And among the indicators measuring dependent variable, the customer aspect was of the highest average (19.56). Growth and learning had the lowest Average (14.54). The standard deviation was 4.13 for the component with the highest average, and 2.71 for the component with the lowest average. The number of observation in each indicator has been 164 (Table 1).

Table 1: Descriptive statistics for the components of social intelligence and organizational performance

\begin{tabular}{|c|c|c|}
\hline measurement Indicator & Mean & $\begin{array}{c}\text { standard } \\
\text { deviation }\end{array}$ \\
\hline $\begin{array}{c}\text { Acceptance of social } \\
\text { information }\end{array}$ & 28.92 & 3.16 \\
\hline Social Skills & 18.7 & 3.35 \\
\hline Social Awareness & 18 & 3.65 \\
\hline Social desirability & 24.63 & 2.74 \\
\hline Growth and Learning & 14.54 & 4.13 \\
\hline customer & 19.56 & 3.96 \\
\hline Financial & 16.32 & 2.71 \\
\hline Internal processes & 14.69 & 3.29 \\
\hline Social Intelligence & 89.64 & 8.13 \\
\hline $\begin{array}{c}\text { Organizational } \\
\text { performance }\end{array}$ & 65.12 & 11.57 \\
\hline
\end{tabular}

\section{Hypothesis testing:}


In order to test the research hypotheses in the current study Pearson correlation test was run. The results obtained for each component and indicators are presented in table 3. The sub- hypotheses which were about existence of any relationship between social skills, social information processing, social awareness and social desirability and organizational performance, were analyzed. The results of analysis showed a positive and significant relationship between social intelligence and organizational performance with a correlation coefficient of 0 . 37. This relationship was approved in the 0.95 confidence interval. The findings of research on the sub-hypotheses revealed direct and meaningful relationships between social skills and organizational performance, social information processing and organizational performance, social awareness and organizational performance, and social desirability and organizational performance with, respectively, the correlation coefficients of $0.19,0.22,0.24$, and 0.34. These coefficients confirmed the sub-hypotheses. The relationship between variables and organizational performance was direct. It means that as the social intelligences increased in four dimensions, the quality of organizational performance improved as well, which was confirmed in $0.95 \%$ confidence interval (table 3 ).

Table 3: Pearson correlation coefficient between the variables of social intelligence and organizational performance

\begin{tabular}{|c|c|c|c|c|c|}
\hline & social skills & $\begin{array}{c}\text { Social information } \\
\text { processing }\end{array}$ & $\begin{array}{c}\text { social } \\
\text { awareness }\end{array}$ & $\begin{array}{c}\text { social } \\
\text { desirability }\end{array}$ & $\begin{array}{c}\text { Social } \\
\text { Intelligence }\end{array}$ \\
\hline $\begin{array}{c}\text { Social Skills } \\
\text { Processing }\end{array}$ & 1 & - & & & \\
\hline Social Awareness & 0.447 & 0.089 & 1 & & \\
\hline Social desirability & 0.382 & 0.345 & 0.179 & 1 & - \\
\hline Social Intelligence & 0.730 & 0.616 & 0.684 & 0.671 & 1 \\
\hline $\begin{array}{c}\text { Organizational } \\
\text { performance }\end{array}$ & 0.191 & 0.229 & 0.243 & 0.349 & 0.375 \\
\hline
\end{tabular}

To investigate the role of social intelligence (predictor variable) in predicting organizational performance (criterion variable), multiple regression analysis with Enter (stepwise) method was performed. The results showed multiple correlation $(\mathrm{R}=0.410)$ between the predictor variable of social intelligence and the criterion variable of organizational performance, which is statistically significant at $\mathrm{P}<0.01$ (Table 4).

In order to identify the aspects of social intelligence that play a decisive role in predicting organizational performance, stepwise multiple regression analysis was employed. As it can be seen in the table below, the first predictor variable entered in the equation is social skills. This variable alone predicts 0.036 of organizational performance distribution (criterion variable) and forms the first model. 
Table 4: Results of regression analysis of predictor variables (social intelligence) and the criterion variable (organizational performance) with stepwise (enter) method

\begin{tabular}{|c|c|c|c|c|c|c|c|c|}
\hline \multirow{2}{*}{$\begin{array}{l}\text { Predictor / } \\
\text { Criterion } \\
\text { Variables }\end{array}$} & \multicolumn{4}{|c|}{ Statistical indices } & \multicolumn{4}{|c|}{ Regression coefficient } \\
\hline & $\mathrm{R}$ & RS & $\mathrm{F}$ & $P$ & 1 & 2 & 3 & 4 \\
\hline Social Skills & 0.191 & 0.036 & 6.13 & 0.872 & $\begin{aligned} \mathrm{B} & =0.872 \\
\mathrm{t} & =2.27 \\
\mathrm{P} & =0.014\end{aligned}$ & & & \\
\hline $\begin{array}{l}\text { Social } \\
\text { Information } \\
\text { Processing }\end{array}$ & 0.270 & 0.073 & 6.31 & 0.002 & $\begin{aligned} \mathrm{B}=0.668 \\
\mathrm{t}=1.87 \\
\mathrm{P}=0.013\end{aligned}$ & $\begin{array}{l}\mathrm{B}=0.716 \\
\mathrm{t}=2.50 \\
\mathrm{P}=0.013\end{array}$ & & \\
\hline $\begin{array}{l}\text { Social } \\
\text { Awareness }\end{array}$ & 0.324 & 0.105 & 6.25 & 0.001 & $\begin{array}{c}\mathrm{B}=0.255 \mathrm{t}= \\
0.653 \\
\mathrm{P}=0.515\end{array}$ & $\begin{array}{l}\mathrm{B}=0.726 \quad \mathrm{t}= \\
2.58 \\
\mathrm{P}=0.011\end{array}$ & $\begin{array}{c}\mathrm{B}=-0.636 \mathrm{t}= \\
2.40 \\
\mathrm{P}=0.018\end{array}$ & \\
\hline $\begin{array}{l}\text { Social } \\
\text { desirability }\end{array}$ & 0.410 & 0.168 & 8.04 & 0.001 & $\begin{array}{l}B=-0.152 \\
t=-0.385 \\
P=0.701\end{array}$ & $\begin{array}{l}\mathrm{B}=0.442 \\
\mathrm{t}=1.55 \\
\mathrm{P}=0.121\end{array}$ & $\begin{array}{l}\mathrm{B}=0.623 \\
\mathrm{t}=2.43 \\
\mathrm{P}=0.016\end{array}$ & $\begin{array}{l}\text { B } \\
=1.19 \\
\mathrm{t} \\
=3.48 \\
\quad \mathrm{P} \\
=0.001\end{array}$ \\
\hline
\end{tabular}

Social information processing that makes the second model, predicts 0.037 of distribution/dispersion of criterion variable and explains 0.073 of dispersion when lies beside the first model. The third variable entered into the equation is social awareness that predicts 0.032 of distribution/dispersion and joined with the two previous model predicts 0.105 of the dispersion of organizational performance. The fourth variable entered into the equation is social desirability that predicts 0.063 of the dispersion, and accompanying the three previous models predicts 0.168 of the distribution of organizational performance (Table 5).

Table 5: Results of stepwise multiple regression analysis for determining dimensions of social intelligence in predicting organizational performance

\begin{tabular}{|c|c|c|c|c|c|}
\hline Model & $\begin{array}{l}\text { Predictor } \\
\text { variables } \\
\text { entered into the } \\
\text { model }\end{array}$ & $\mathrm{R}$ value & R2 & $\mathrm{F}$ & Sig \\
\hline A & social skills & 0.191 & 0.036 & 6.13 & 0.014 \\
\hline B & $\begin{array}{c}\text { Social } \\
\text { Information } \\
\text { Processing }\end{array}$ & 0.270 & 0.073 & 6.31 & 0.002 \\
\hline $\mathrm{C}$ & $\begin{array}{c}\text { Social } \\
\text { Awareness }\end{array}$ & 0.324 & 0.105 & 6.25 & 0.001 \\
\hline $\mathrm{D}$ & $\begin{array}{c}\text { Social } \\
\text { desirability }\end{array}$ & 0.410 & $8 / 04$ & $0 / 168$ & 0.001 \\
\hline
\end{tabular}

Criterion variable: organizational performance

a. Determiners: social skills. 
b. Determiners: Social skills and social information processing.

c. Determiners: Social skills, social information processing social awareness.

d. Determiners: Social skills, social information processing social awareness and social desirability.

\section{Conclusion and recommendations}

The relationship between sub-variables of social intelligence and organizational performance were approved as follows: social skills and organizational performance with correlation coefficient of 0.19 , social information processing and organizational performance with correlation coefficient of 0.22 , social awareness and organizational performance with correlation coefficient of $24 / 0$, and social desirability and organizational performance with a correlation coefficient of 0.34 . i.e., the greater social intelligence increases, the higher quality of organizational performance is. And the relationship was confirmed in the 0.99 confidence interval which shows the main hypotheses and sub-hypotheses' being supported. Multiple regression analysis with stepwise method was used repeatedly, to investigate the role of social intelligence (predictor variable) in predicting organizational performance (criterion variables). The results revealed multiple relations between the variables of social intelligence and the criterion variable of organizational performance $(\mathrm{MR}=0.410, \mathrm{P}<0.0001)$ which were statistically significant. Furthermore, the analysis of the results indicated that the predictor of social skills predicted 0.036 of organizational performance (criterion variable), the social information processing made the second model and predicted 0.037 of the degree of dispersion/distribution of criterion variable (organizational performance) and explained 0.073 of dispersion, accompanying the first model. Social awareness alone predicted 0.032 of dispersion and joined with the two previous model predicted 0.105 of the dispersion of organizational performance. Social desirability that predicted 0.063 of the dispersion, along with the three previous models predicted 0.168 of the distribution of organizational performance. Therefore, it can be claimed that 0.168 of distribution of organizational performance in this study was predicable by four variables of social skills, social information processing, social awareness, and social desirability.

According to the achieved results, it can be suggested more attention to be devoted on those social intelligence variables which have the greatest effect on organizational performance. In this inspection, the social desirability was first in ranking the variables. Hence, to maximize organizational performance, managers need to direct their attention and investment to social desirability. As such, the satisfaction of staff and customers with the services provided by the company would rise as well. Directing attention to social desirability can enhance unity and solidarity among managers and staff and lead to improved organizational performance. The second variable or factor that companies need to pay attention to is social awareness. In this regard, it is essential the value of offered services to be perceived by staff, so that they can have an appropriate measure/ a criterion for comparing the received services with services offered by competitors. Two other variables, as well, must be considered in order of priority. Thus, to increase efficiency and profitability, and ultimately improvement of organizational performance, managers should take the mentioned aspects into consideration and accentuate these dimensions, while planning to offer services. Moreover, to have a better performance, managers should try to control their emotions. It is recommended that in order to achieve organizational efficiency not only the mangers should be trained on the technical skills, but also on the social skills to understand each other, pursue common goals and trust in each other. Through proper planning, a situation in the organization should be provided in which staff is seeking for new ideas and viewpoints, clear feedbacks, and constant training, particularly, on social intelligence. 
Additionally, it is proposed that senior organizational managers create a situation in which the staff of important social networks can be identified. It is apparent that attending to this issue makes the index of organizational awareness rise. Developing effective programs, providing necessary condition and appropriate training for managing tensions and crises created by incompatible individuals via adopting appropriate measures with the purpose of improving the staff's performance and the management condition are positive results of managing and controlling social relations based on social intelligence.

\section{References}

Aristu, A.L, Tello, F.P.H \& Orttiz, M.A.,\& Gandarn, M. (2008). The Structure of Bryants Empathy Index For Children: Acroo-Validation Study, Journal of psychology, vol 11, No 2, pp 670-677.

Beheshtifar, M, Roasaei, F. (2012). Role of Social Intelligence in Organizational Leadership, European Journal of Social SciencesVol.28 No.2, pp. 200-206

Brown, B. (2005). Emotional Intelligence: Implication for Human Resource Development, Otago Management Graduate Review, Vol.3, No.4, PP.21-36.

Gini, G.(2005). Adaptation of the Italian Version of the Troms Social Intelligence Scale to the adolescent population, Journal of Adolescence, 29, PP307-312.

Goleman, D. (1998): What makes a leader? Harvard Business Review, November- December, No77, PP.93-102.

Hsien, H.W .(2008). The Impact of other- customer failure on service satisfaction, International Journal of Service Industry Managemen, vol.196 No.4, PP.521- 536.

Ho, L. (2008). what affects organizational performance? Industrial Management \& Data System, 108-118.

Nasel, D. D. (2004). Spiritual Orientation in Relation to Spiritual Intelligence: A consideration of traditional Christianity and New Age/individualistic spirituality. Thesis submitted for the degree of Ph. D in The University of South Australia, Division of Education, Arts and Social Sciences, School of Psychology.

Neely, A, D, Adams, C, Kennerly, M.(2002).The performance primes: The scorecard for measuring and managing stakeholder relationship, Financial Times/ Prentice Hall, London.

Nwkah, N.G., Ahiauzu, A.L.(2009).Emotional intelligence and marketing effectives, Marketing Intelligence \& Planning, Vol. 27, PP: 867-881.

Shall, H. Z.(2010).Defining Social Intelligence Driving Customer Insight Through Social Media Data, Forrester Research, Inc. Reproduction Prohibited, pp.1-14.

Shutte, N.S., Malouff, J. M., Hall, L. E., Haggerty, D.J., Cooper, J.T., Golden, C.J.,\& Dornheim, L. (1998).Development and validation of a measure of emotional intelligence. personality and Individual Differences, 25, 167- 177. 